\title{
ANALISIS SISTEM SALURAN DRAINASE PADA PERUMAHAN BATURAJA PERMAI DIKOTA BATURAJA KABUPATEN OGAN KOMERING ULU
}

\author{
Lucyana \\ Program Studi Teknik Sipil Fakultas Teknik dan Komputer \\ Universitas Baturaja Sumatera Selatan \\ Email: lucyana@unbara.ac.id
}

\begin{abstract}
ABSTRAK
Seiring dengan berkembangnya infrastruktur di Kota Baturaja tepatnya di Perumahan Baturaja Permai, yang diiringi pula dengan meningkatnya jumlah penduduk, maka menyebabkan semakin bertambah pula kegiatan dan kebutuhannya. Saat ini salah satu permasalahan yang dihadapi diperumahan Baturaja Permai adalah timbulnya genangan saat hujan turun. Hal ini dikarenakan dampak perubahan tata guna lahan yang menyebabkan berkurangnya infiltrasi tanah. Sehingga saluran-saluran drainase yang ada dipenuhi oleh sedimentasi dan juga sampah-sampah, akibatnya saluran tidak dapat bekerja optimal untuk mengalirkan air hujan yang ada. Jenis penelitian yang dilakukan adalah studi kasus di Perumahan Baturaja Permai tepatnya di jalan Kol. H. Mulkan Aziman, Kecamatan Baturaja Timur, Kelurahan Baturaja Permai, Kabupaten Ogan Komering Ulu. Metode yang dipakai adalah deskriptif, yaitu metode yang menjelaskan kondisi obyektif (sebenarnya) pada suatu keadaan yang menjadi objek studi.Berdasarkan hasil analisa yang dilakukan, diperoleh kesimpulan bahwa Luas Perumahan Baturaja Permai yaitu $12.000 \mathrm{~m}^{2}$. Debit pada saluran drainase primer yaitu $0,561 \mathrm{~m}^{3} /$ dtk dengan $B=1,4 \mathrm{~m}, H=2,6 \mathrm{~m}$ dan $W=0,3 \mathrm{~m}$. Debit pada saluran drainase sekunder 1 yaitu $1,0233 \mathrm{~m}^{3} / d t k$ dengan $B=0,9 \mathrm{~m}, H=1,05 \mathrm{~m}$ dan $W=0,1 \mathrm{~m}$. Debit pada saluran drainase sekunder 2 yaitu $0,6987 \mathrm{~m}^{3} / d t k$ dengan $B=0,8 m, H=0,9 m$ dan $W=0,1 \mathrm{~m}$. Debit air kotor yaitu sebesar $0,000218 \mathrm{~m}^{3} / \mathrm{dtk}$.
\end{abstract}

Kata Kunci : Perumahan, Debit, Drainase

\section{PENDAHULUAN}

Drainase merupakan infrastuktur yang sangat penting bagi suatu wilayah. Secara umum, drainase didefinisikan sebagai ilmu pengetahuan yang mempelajari usaha untuk mengalirkan air yang berlebihan dalam suatu konteks pemanfaatan tertentu. Sedangkan drainase perkotaan adalah ilmu drainase yang mengkhususkan pegkajian pada kawasan perkotaan yang erat kaitannya dengan kondisi Lingkungan Fisik dan Lingkungan Sosial Budaya yang ada di kawasan kota tersebut (s.n,1997,hlm.3). Suatu sistem drainase yang baik haruslah mampu menampung dan mengalirkan air semaksimal mungkin, sehingga tidak akan terjadi genangan air dan banjir saat hujan turun.

Seiring dengan berkembangnya infrastruktur di Kota Baturaja tepatnya di Perumahan Baturaja Permai, yang diiringi pula dengan meningkatnya jumlah penduduk, maka menyebabkan semakin bertambah pula kegiatan dan kebutuhannya. Saat ini salah satu permasalahan yang dihadapi diperumahan Baturaja Permai adalah timbulnya genangan saat hujan turun. Hal ini dikarenakan dampak perubahan tata guna lahan yang menyebabkan berkurangnya infiltrasi tanah. Sehingga saluran-saluran drainase yang ada dipenuhi oleh sedimentasi dan juga sampah-sampah, akibatnya saluran tidak dapat bekerja optimal untuk mengalirkan air hujan yang ada.

Saat ini begitu banyak saluran drainase yang keadaannya tidak baik dan kurang terawat, serta sudah tidak mampu lagi menampung air hujan, sehingga air meluap dan 
menyebabkan terjadinya genangan. Maka saluran drainase yang ada harus di evaluasi apakah kapasitasnya mampu menampung debit rencana atau tidak. Drainase merupakan infrastuktur yang sangat penting bagi suatu wilayah. Secara umum, drainase didefinisikan sebagai ilmu pengetahuan yang mempelajari usaha untuk mengalirkan air yang berlebihan dalam suatu konteks pemanfaatan tertentu. Sedangkan drainase perkotaan adalah ilmu drainase yang mengkhususkan pegkajian pada kawasan perkotaan yang erat kaitannya dengan kondisi Lingkungan Fisik dan Lingkungan Sosial Budaya yang ada di kawasan kota tersebut (s.n,1997,hlm.3). Suatu sistem drainase yang baik haruslah mampu menampung dan mengalirkan air semaksimal mungkin, sehingga tidak akan terjadi genangan air dan banjir saat hujan turun.

Seiring dengan berkembangnya infrastruktur di Kota Baturaja tepatnya di Perumahan Baturaja Permai, yang diiringi pula dengan meningkatnya jumlah penduduk, maka menyebabkan semakin bertambah pula kegiatan dan kebutuhannya. Saat ini salah satu permasalahan yang dihadapi diperumahan Baturaja Permai adalah timbulnya genangan saat hujan turun. Hal ini dikarenakan dampak perubahan tata guna lahan yang menyebabkan berkurangnya infiltrasi tanah. Sehingga saluran-saluran drainase yang ada dipenuhi oleh sedimentasi dan juga sampah-sampah, akibatnya saluran tidak dapat bekerja optimal untuk mengalirkan air hujan yang ada.

Saat ini begitu banyak saluran drainase yang keadaannya tidak baik dan kurang terawat, serta sudah tidak mampu lagi menampung air hujan, sehingga air meluap dan menyebabkan terjadinya genangan. Maka pada perumahan baturaja permai saluran drainase yang ada harus di evaluasi apakah kapasitasnya mampu menampung debit rencana atau tidak.

\section{TINJAUAN PUSTAKA}

\section{Pengertian Drainase}

Drainase (drainage) yang berasal dari kata kerja/to drain' yang berarti mengeringkan atau mengalirkan air, adalah termologi yang dipergunakan untuk menyatakan sistem-sistem yang berkaitan dengan penanganan masalah kelebihan air, baik diatas maupun dibawah permukaan tanah. Drainase merupakan salah satu fasilitas dasar yang dirancang sebagai sistem guna memenuhi kebutuhan masyarakat dan merupakan komponen penting dalam perencanaan kota (perencanaan insfrastruktur khususnya). Menurut (Dr. Ir. Suripin, M.Eng. 2004;7) drainase mempunyai arti mengalirkan, menguras, membuang atau mengalirkan air.

Menurut Hasmar,H (2011:8) dalam Amiwarti (2017) drainase dibagi dalam beberapa bagian :

1. Menurut Sejarah Terbentuknya

a. Drainase alamiah (Natural Drainage)

Drainase alamiah adalah sistem drainase yang terbentuk secara alami dan tidak terdapat bangunan penunjang seperti bangunan pelimpah, pasangan batu/beton, gorong-gorong, dan lain-lain. Saluran ini terbentuk oleh gerusan air yang bergerak karena gravitasi yang lambat laun membentuk jalan air yang permanen seperti sungai. 
b. Drainase buatan (Artificial Drainage)

Drainase yang dibuat dengan maksud dan tujuan tertentu sehingga memerlukan bangunan-bangunan khusus seperti selokan pasangan batu/beton, gorong-gorong, pipa-pipa dan sebagainya. Adapun yang mempengaruhi perencanaan dan perhitungan saluran buatan ini adalah tingkat kedalaman, luas lahan air, kemiringan saluran, debit, distribusi aliran penyumbatan dan kecepatan air.

2. Menurut Letak Bangunan

a. Drainase permukaan tanah (Surface Drainage)

Drainase permukaan tanah adalah saluran drainase yang berada di atas permukaan tanah yang berfungsi mengalirkan air limpasan permukaan. Analisa alirannya merupakan analisa open channel flow.

b. Drainase bawah tanah (Sub Surface Drainage)

Drainase bawah tanah adalah saluran drainase yang bertujuan mengalirkan air limpasan permukaan melalui media di bawah permukaan tanah (pipa-pipa), dikarenakan alasan-alasan tertentu. Alasan tersebut antara lain tuntutan artistik, tuntutan fungsi permukaan tanah yang tidak membolehkan adanya saluran di permukaan tanah seperti lapangan sepak bola, lapangan terbang, taman, dan lainlai

3. Menurut Fungsinya

a. Single Purpose

Saluran berfungsi mengalirkan satu jenis air buangan saja, misalnya air hujan atau jenis air buangan lain seperti air limbah domestik, air limbah industry dan lainlain.

b. Multy Purpose

Saluran berfungsi mengalirkan beberapa jenis buangan, baik secara bercampur maupun bergantian.

4. Menurut Konstruksinya

a. Saluran Terbuka adalah sistem saluran yang biasanya direncanakan hanya untuk menumpang dan mengalirkan air hujan (sistem terpisah), namun kebanyakan sistem saluran ini berfungsi sebagai saluran campuran. Pada pinggiran kota, saluran terbukaini biasanya tidak diberi lining (lapisan pelindung). Akan tetapi saluran terbuka di dalam kota harus diberi lining dengan beton, pasangan batu (masonry) ataupun dengan pasangan bata.

b. Saluran Tertutup adalah saluran untuk air kotor yang mengganggu kesehatan lingkungan. Sistem ini cukup bagus digunakan di daerah perkotaan terutama dengan tingkat kepadatan penduduk yang tinggi seperti kota Metropolitan dan kotakota besar lainnya.

5. Menurut Penataan Jaringannya

a. Jaringan primer yaitu saluran yang memamfaatkan sungai dan anak sungai. Saluran ini merupakan saluran induk dari saluran air yang berasal dari saluran sekunder dan tersier. Jadi dimensi saluran primer ini harus memiliki ukuran lebih besar.

b. Saluran sekunder yaitu saluran ynag menghubungkan saluran tersier dengan 
saluran primer yang dibangun dengan beton/plesteran semen. Saluran ini merupakan cabang dari saluran primer untuk mengalirkan air dari daerah sekunder ke daerah saluran pimer.

c. Saluran tersier yaitu saluran untuk mengalirkan limbah rumah tangga kesaluran sekunder. Saluran ini merupakan cabang dari saluran sekunder, saluran tersier ini mempunyai ukuran yang lebih kecil dari saluran sekunder dan primer.

d. Saluran kuarter yaitu saluran cabang dari saluran tersier, saluran ini lebih kecil dari saluran tersier yang letak dirumah-rumah penduduk yang berupa plesteran, pipa dan tanah.

6. Menurut Pola Jaringan

Beberapa contoh model tata letak jalur saluran yang dapat diterapkan dalam perencanaan drainase sebagai berikut.

a. Pola Alamiah

Letak conveyor drain ada di bagian terendah (lembah) dari suatu daerah (alam) yang efektif berfungsi sebagai pengumpul dari anak cabang saluran yang ada (collector drain).

b. Pola Siku

Conveyor drain terletak di bagian terendah (lembah). Sedangkan collector drain dibuat tegak lurus conveyor drain.

c. Pola Pararel

Collector drain menampung debit air yang lebih kecil. Collector drain dibuat sejajar satu sama lain dan kemudian debit air yang lebih kecil masuk ke conveyor drain.

d. Pola Grid Iron

Beberapa interceptor drain dibuat sejajar satu sama lain, kemudian ditampung di collector drain untuk selanjutnya masuk ke dalam conveyor drain.

e. Pola Radial

Satu daerah genangan dikeringkan melalui beberapa collector drain dari sat titik meyebar ke segala arah (sesuai dengan kondisi topografi daerah).

f. Pola Jaring-jaring

Untuk mencegah terjadinya pembebanan aliran di suatu daerah terhadap daerah lainnya, maka dapat dibuat beberapa interceptor drain yang kemudian ditampung ke dalam saluran collector drain dan selanjutnya dialirkan menuju saluran conveyor drain.

\section{Faktor Yang Mempengaruhi Perencanaan Drainase}

Dalam merencanakan saluran drainase perlu diperhatikan beberapa hal untuk menjamin saluran drainase berfungsi sebagaimana mestinya.

1. Koefisien Pengaliran ( C )

Besarnya debit aliran pada suatu daerah sangat diperlukan untuk menentukan demensi saluran. Oleh karena itu, kita memerlukan koefisien pengaliran untuk dapat menghitung debit aliran itu. Besarnya pengaliran dapat dinyatakan dengan ukuran tinggi. Kita sebut aliran tinggi, kalau ukuran besarnya hujan (dalam mm) untuk daerah 
luas yang sama kita sebut tinggi hujan. Maka perbandingan antara tinggi aliran dan tinggi hujan untuk jangka waktu cukup panjang disebut angka pengaliran, jadi:

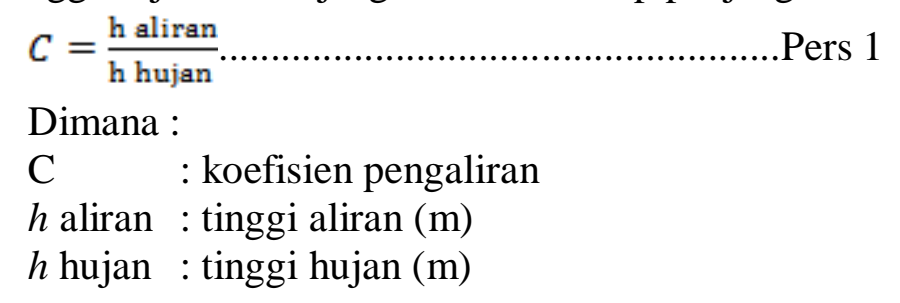

2. Bentuk Saluran

Saluran untuk drainase tidak terlampau jauh berbeda dengan saluran air lainnya pada umumnya. Dalam perancangan dimensi saluran harus diusahakan dapat memperoleh dimensi tampang yang ekonomis. Dimensi saluran yang erlalu besar berarti tidak ekonomis, sebaliknya dimensi saluran yang terlalu kecil tingkat kerugian akan besar. Efektifitas penggunaan dari berbagai bentuk tampang

\section{Analisis Hidrologi}

Analisis hidrologi adalah kumpulan keterangan atau fakta mengenai fenomena hidrologi (Suripin, 2004). Fenomena hidrologi sebagai mana telah dijelaskan di bagian sebelumnya adalah kumpulan keterangan atau fakta mengenai fenomena hidrologi. Fenomena hidrologi seperti besarnya curah hujan, temperature, penguapan, lama penyinaran matahari, kecepatan angin, debit sungai, tinggi muka air, akan selalu berubah menurut waktu. Untuk suatu tujuan tertentu data-data hidrologi dapat dikumpulkan, dihitung, disajikan, dan ditafsirkan dengan menggunkan prosedur tertentu

\section{Analisis Hujan Rata-Rata}

Hujan merupakan komponen yang amat penting dalam analisis hidrologi pada perancangan debit untuk menentukan dimensi saluran drainase. Mengingat hujan sangat bervariasi terhadap tempat (space), maka untuk kawasan sangat luas tidak bisa diwakili satu titik pos pengukuran. Dalam hal ini diperlukan hujan kawasan yang diperoleh dari harga rata-rata curah hujan beberapa pos pengukuran hujan yang ada disekitar kawasan tersebut. Ada 3 macam cara yang umum dipakai dalam menghitung hujan rata-rata kawasan : (1) rata-rata aljabar, (2) poligon thiessen dan (3) isohyet. Curah Hujan Maksimum Harian Rata-Rata .Curah hujan diperlukan untuk menentukan besarnya intensitas yang digunakan sebagai prediksi timbulnya aliran permukaan wilayah. Curah hujan yang digunakan dalam analisis adalah curah hujan harian maksimum rata-rata dalam satu tahun yang telah dihitung. Perhitungan data hujan maksimum harian rata-rata harus dilakukan secara benar untuk analisis frekuensi data hujan.

\section{Analisis Frekuensi dan Probabilitas}

Tujuan analisis frekuensi data hidrologi adalah berkaitan dengan besaran peristiwaperistiwa ekstrim yang berkaitan dengan frekuensi kejadiannya melalui penerapan distribusi kemungkinan. Data hidrologi yang dianalisis diasumsikan tidak bergantung (independent) dan terdistribusi secara acak serta bersifat stokastik. Analisis frekuensi diperlukan seri data hujan yang diperoleh dari pos pengukuran hujan, baik manual maupun otomatis. Analisis frekuensi ini didasarkan pada sifat statistik data kejadian yang telah lalu 
untuk memperoleh probabilitas besaran hujan di masa yang akan datang. Dengan anggapan bahwa sifat statistik kejadian hujan yang akan datang masih sama dengan sifat statistik kejadian hujan masa lalu.

Intensitas Hujan

Intensitas hujan adalah tinggi atau kedalaman air hujan per satuan waktu. Sifat umum hujan adalah makin singkat hujan berlangsung, intensitasnya cenderung makin tinggi dan makin besar periode ulangnya makin tinggi pula intensitasya. Seandainya data hujan yang diketahui hanya hujan harian, maka oleh Mononobe dirumuskan sebagai berikut:

$$
I=\frac{R_{24}}{24}\left(\frac{24}{t}\right)^{\frac{2}{3}}
$$
Pers 2

$$
\text { Dengan : } \quad \begin{aligned}
\mathrm{I} & =\text { Intensitas hujan }(\mathrm{mm} / \mathrm{jam}) \\
\mathrm{t} & =\text { Lamanya hujan }(\mathrm{jam}) \\
\mathrm{R} 24 & =\text { curah hujan maksimum harian dalam } 24 \text { jam }(\mathrm{mm})
\end{aligned}
$$

Jika data yang tersedia adalah data hujan jangka pendek dapat dihitung dengan menggunakan rumus Talbot:

$$
\begin{aligned}
& I=\frac{a}{t+b} \text {. } \\
& \text { Dengan : } \quad I=\text { Intensitas hujan }(\mathrm{mm} / \mathrm{jam}) \\
& \mathrm{t}=\text { Lamanya hujan (jam) } \\
& a \text { dan } b=\text { konstanta yang tergantung pada lamanya hujan yang terjadi di DAS }
\end{aligned}
$$

\section{Waktu Konsentrasi}

Kirpich (1940) dalam Suripin (2004) mengembangkan rumus dalam memperkirakan waktu konsentrasi, dimana dalam hal ini durasi hujan diasumsikan sama dengan waktu konsentrasi. Rumus waktu konsentrasi tersebut dapat ditulis sebagai berikut:

$$
t_{c}=\left(\frac{0,8 \cdot L^{2}}{1000 \cdot s_{0}}\right)^{0,385}
$$
Pers 4

Dengan : $\quad$ tc $=$ waktu konsentrasi $(j a m)$

$\mathrm{L}=$ panjang saluran utama dari hulu sampai penguras $(\mathrm{km})$

So $=$ kemiringan rata-rata saluran

\section{Hujan Rata-Rata Daerah Aliran}

Cara yang dipakai dalam menghitung hujan rata-rata adalah dengan Rata-rata Aljabar, Polygon Thiessen dan Ishohyet, biasa digunakan untuk daerah-daerah dimana titik-titik dari pengamat hujan tersebar merata dan hasilnya pun lebih teliti. Adapun caranya, yaitu :

1. Cara Rata-Rata Aljabar

Cara yang paling sederhana adalah adalah dengan melakukan perhitungan rata - rata arimatik (aljabar) dari rerata presipitasi yang diperoleh dari seluruh alat penakar hujan yang digunakan. Cara ini dianggap cukup memadai sepanjang digunakan di daerah yang relative landai dengan variasi curah hujan yang tidak terlalu besar serta penyebaran alat penakar hujan diusahakan seragam.

$$
\bar{R}=\frac{1}{n}+\left(\mathrm{R}_{1}+\mathrm{R}_{2}+\ldots .+\mathrm{Rn}\right) \ldots \ldots \ldots \ldots \ldots \ldots . . . \text { Pers } 5
$$

$$
\begin{array}{lll}
\text { Keterangan }: & =\text { Curah hujan rata-rata rendah } \\
& \overline{\mathrm{n}} & =\text { Jumlah tiktik atau pos pengamatan } \\
\mathrm{R} 1, \mathrm{R} 2, \ldots, \mathrm{Rn} & =\text { Curah hujan tiap titik pengamatan }
\end{array}
$$


2. Cara Thiessen

Metode ini digunakan secara luas karena dapat memberikan data memberikan data presipitasi yang lebih akurat, karena setiap bagian wilayah tangkapan hujan diwakili secara proposional oleh suatu alat penakar hujan. Dengan cara ini, pembuatan gambar polygon dilakukan sekali saja, sementara perubahan data hujan per titik dapat diproses secara cepat tanpa menghitung lagi luas perbagian poligon.

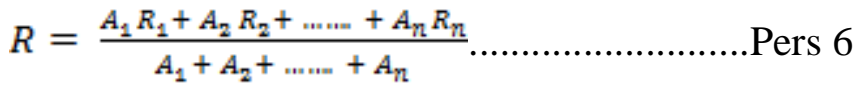

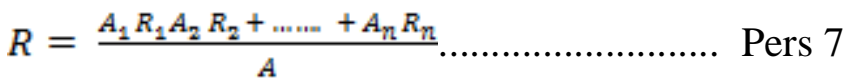

$$
\begin{aligned}
& R=W_{1} R_{1}+W_{2} R_{2}+\ldots \ldots+W_{n} R_{n} \ldots \ldots \ldots . . . \text { Pers } 8
\end{aligned}
$$

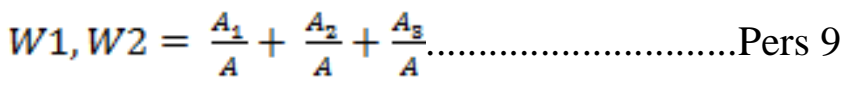

$$
\begin{array}{ll}
\text { Keterangan: } & \begin{array}{l}
\mathrm{R} \\
\mathrm{R} 1, \mathrm{R} 2, \mathrm{R} 3
\end{array} \\
& =\text { Curah hujan rerata tahunan }(\mathrm{mm}) \\
\mathrm{R} & =\text { Jumlah titik pengamatan } \\
\mathrm{A} 1, \mathrm{~A} 2 & =\text { Luas wilayah yang dibatasi polygon } \\
\mathrm{A} & =\text { Luas daerah penelitian }
\end{array}
$$

3. Cara Isohyet

Peta Isohyet digambarkan pada peta topografi berdasarkan data curah hujan (interval $10-20 \mathrm{~mm}$ ) pada titik pengamatan di dalam dan sekitar daerah yang dimaksud. Luas bagian daerah antara dua garis isohyets yang berdekatan diukur dengan planimeter. Harga rata - rata dari garis - garis isohyets yang berdekatan yang termasuk bagian bagian daerah itu dapat dihitung. Curah hujan daerah dihitung menurut persamaan seperti dibawah ini.

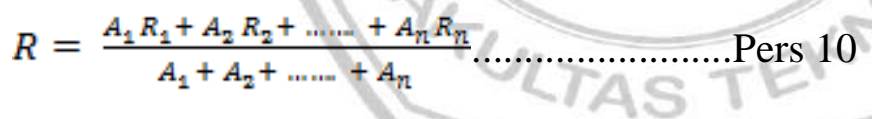

$$
\begin{aligned}
& \text { Keterangan : } \mathrm{R}=\text { Curah hujan rerata tahunan } \\
& \mathrm{A} 1, \mathrm{~A} 2=\text { Luas bagian antar dua garis isohyets } \\
& \mathrm{R} 1, \mathrm{R} 2, \mathrm{Rn}=\text { Curah hujan rata2 tahunan pada bagian } \mathrm{A} 1, \mathrm{~A} 2, \ldots, \mathrm{An}
\end{aligned}
$$

\section{Analisa Frekuensi (Curah Hujan Rencana)}

Dalam statistik terdapat beberapa jenis sebaran (distribusi), diantaranya yang sering digunakan dalam hidrologi adalah :

1. Distribusi Probabilitas Normal

Dalam analisis hidrologi distribusi normal sering digunakan untuk menganalisis frekuensi curah hujan, analisis 34tatistic dari distribusi curah hujan tahunan, debit rata-rata tahunan.

Rumus yang digunakan dalam perhitungan :

$\mathrm{R}_{\mathrm{i}} \mathrm{x}=\overline{R_{l}}+\mathrm{SxK}$ Pers 11 
Keterangan :

$\mathrm{Ri}=$ Nilai curah hujan maksimum $(\mathrm{mm})$

$\overline{R l}=$ Nilai curah hujan maksimum rata-rata $(\mathrm{mm})$

$\mathrm{s}=$ Standar deviasi

$\mathrm{n}=$ Jumlah data pengamatan

2. Distribusi Normal

Distribusi Normal atau disebut pula Distribusi Gauss, dalam analisis hidrologi Dibusi Normal sering digunakan untuk menganalisis frekuensi curah hujn, analisis statistik dari distribusi curah hujan tahunan, debit rata-rata tahunan.

Nilai faktor frekuensi $\mathrm{K}_{\mathrm{T}}$ pada perhitungan Distribusi Normaumumnya sudah tersedia dalam tabel yang sudah tersedia untuk mempermudah perhitungan yang umum disebut sebagai tabel Variabel Reduksi Gauss (Variable Reduce Gauss).

Langkah-langkah menggunakan metode Distribusi Normal :

a). Hitung harga rata-rata curah hujan

$$
\begin{aligned}
& \overline{\mathrm{R}}_{\mathrm{i}} \quad={ }_{\mathrm{n}}^{-} \sum_{\overline{\mathrm{i}}=1}^{\mathrm{n}} \mathrm{R}_{\mathrm{i}} . \\
& \text { Keterangan : } \\
& \overline{\mathrm{R}}_{\mathrm{i}} \quad=\text { Curah hujan rata-rata(mm/tahun) } \\
& \mathrm{n} \quad=\text { Banyaknya data atau panjang data } \\
& \mathrm{R}_{\mathrm{i}} \quad=\text { Curah hujan }(\mathrm{mm})
\end{aligned}
$$

b). Hitung harga simpanan baku curah hujan

$$
S=\sqrt{\frac{\sum_{\bar{i}=1}^{n}\left(R_{i}-\bar{R}_{i}\right)}{n-1}} \ldots \text { P GR }
$$

Keterangan :

$\mathrm{S}$ = Standar deviasi / simpangan baku

$\mathrm{n} \quad$ = Banyaknya data atau panjang data

$\mathrm{R}_{\mathrm{i}} \quad=$ Curah hujan( $\left.\mathrm{mm}\right)$

$\overline{\mathrm{R}}_{\mathrm{i}} \quad=$ Curah hujan rata-rata $(\mathrm{mm})$

c). Hitung curah hujan dengan metode Distribusi Normal

$\mathrm{R}_{\mathrm{T}}=\overline{\mathrm{R}}_{\mathrm{I}}+\mathrm{K}_{\mathrm{T}} \cdot \mathrm{S}$ Pers 14

Keterangan :

$\mathrm{R}_{\mathrm{T}}=$ Curah hujan untuk periode ulang $\mathrm{T}$-tahun (mm)

$\overline{\mathrm{R}}_{\mathrm{i}} \quad=$ Curah hujan rata-rata(mm)

$\mathrm{K}_{\mathrm{T}}=$ Faktor frekuensi

$\mathrm{S}$ = Standar deviasi / simpangan baku

3. Distribusi log Person III

Distribusi log pearson type III digunakan untuk analisis variabel hidrologi dengan varian minimum misalnya, analisis frekunsi distribusi dari debit minimum (low flow). Langkah-langkah menggunakan log person III :

a). Ubah data dalam bentuk logaritmis, $R=\log R_{i}$

b). Hitung harga rata-rata: 
$\log \overline{\mathrm{R}}=\frac{\sum_{i=\mathbb{1}}^{\mathrm{n}} \log R i}{n}$. Pers 15

c). Hitung harga standar deviasi :

$$
\mathrm{S}=\left[\frac{\sum_{i=1}^{n}(\log R i-\log \overline{\mathrm{R}} i) 2}{n-1}\right]^{-0,5}
$$

4. Distribusi gumble

Langkah-langkah menggunakan metode Distribusi Gumbel :

a). Hitung harga rata-rata curah hujan

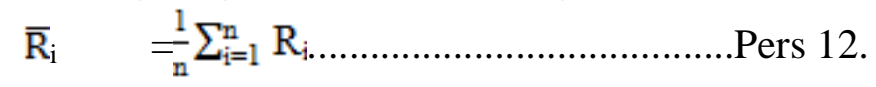

Keterangan :

$\overline{\mathrm{R}}_{\mathrm{i}} \quad=$ Curah hujan rata-rata $(\mathrm{mm})$

$\mathrm{n} \quad=$ Banyaknya data atau panjang data

$\mathrm{R}_{\mathrm{i}} \quad=$ Curah hujan $(\mathrm{mm})$

b). Hitung harga simpanan baku curah hujan

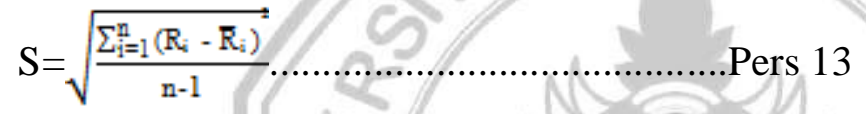

Keterangan :

$\mathrm{S}=$ Standar deviasi / simpangan baku

$\mathrm{n} \quad=$ Banyaknya data atau panjang data

$\mathrm{R}_{\mathrm{i}} \quad=$ Curah hujan $(\mathrm{mm})$

$\overline{\mathrm{R}}_{\overline{\mathrm{i}}} \quad=$ Curah hujan rata-rata $(\mathrm{mm})$

c). Hitung curah hujan dengan metode Gumbel

$$
\mathrm{R}_{\mathrm{T}}=\overline{\mathrm{R}}_{\mathrm{i}}+\frac{\mathrm{s}}{\mathrm{Sn}_{\mathrm{n}}}\left(\mathrm{YT}_{\mathrm{r}}-\mathrm{Y}_{\mathrm{n}}\right)
$$

Keterangan :

$\mathrm{R}_{\mathrm{T}} \quad=$ Nilai curah hujan untuk periode ulang $\mathrm{T}$-tahun(mm/tahun)

$\mathrm{Y}_{\mathrm{tr}} \quad=$ Nilai Reduced Variete

$\mathrm{Y}_{\mathrm{n}} \quad=$ Nilai Reduced Mean

$\mathrm{S}_{\mathrm{n}} \quad=$ Nilai Reduced Standard Deviation

$\mathrm{N} \quad=$ Jumlah data pengamatan

5. Debit Aliran (Debit Hujan)

Pada area yang masih alami besarnya debit banjir cenderung lebih kecil dibandingkan dengan area yang sudah dikembangkan pada kondisi kemiringan yang sama. Untuk daerah kawasan meresapnya air diperkirakan sedikit dan konsentrasinya pendek, sehingga keseimbangan air sering kali tidak tercapai. Metode yang digunakan adalah metode rasional dengan formula sebagai berikut:

$Q=0,278$ C.I.A $\left(\mathrm{m}^{3} /\right.$ detik $)$. Pers 19 
Dimana :

$\mathrm{Q}=$ debit yang mengalir kedalam saluran $\left(\mathrm{m}^{3} /\right.$ detik $)$

$\mathrm{C}=$ koefisien pengaliran

I $\quad=$ intensitas hujan ( $\mathrm{mm} /$ hujan)

A $\quad=$ luas daerah aliran $\left(\mathrm{km}^{2}\right)$

6. Debit Air Limbah Rumah Tangga

Debit air limbah rumah tangga didapt dari jumlah 60\% - 70\% suplay air bersih setiap orang, diambil $70 \%$ saja, sisanya dipakai pada proses industri, penyiraman kebun dan lain-lain dengan rumus:

Qair kotor $=$ jum orang $x$ air bersih $x 70 \% .18$

7. Debit Saluran/Kapasitas Saluran

Kapasitas saluran didapat setelah melakukan pengukuran dimensi saluran dilapangan. Penaksiran kapasitas saluran pada sebagian penampang melintang adalah dengan mengandaikan bahwa aliran saluran dalam kondisi seragam (uniform flow).

Rumus yang digunakan secara umum untuk perhitungan hidrolika pada penampang saluran yang seragam digunakan persamaan manning, dengan mengalirkan kecepatan aliran dengan luas penampang basah.

Persamaan Manning

Dimana :

$$
\begin{aligned}
& V=\frac{1}{n} R^{\frac{2}{a}} S^{\frac{1}{2}} \\
& \mathrm{~V}=\text { kecepatan rata-rata (m/detik) } \\
& \mathrm{n} \quad=\text { koefisien kekerasan manning } \\
& \mathrm{R}=\text { jari-jari hidrolis }(\mathrm{m}) \\
& \mathrm{S} \quad=\text { kemiringan dasar saluran }
\end{aligned}
$$

\section{METODE PENELITIAN}

\section{Lokasi Penelitian}

Penelitian ini dilakukan di Perumahan Baturaja Permai tepatnya di jalan Kol. H. Mulkan Aziman, Kecamatan Baturaja Timur, Kelurahan Baturaja Permai, Kabupaten Ogan Komering Ulu. Penelitian di mulai dari survei kondisi daerah penelitian, pengumpulan data-data, analis hidrologi, analisis sistem pengaliran, evaluasi sistem drainase yang ada.

\section{Teknik Analisis Data}

Tahapan mengolah data yang telah dikumpulkan dari lokasi penelitian (data primer dan data sekunder) guna untuk menganalisa sistem saluran drainase perumahan. Tahapan analisa data meliputi:

a. Analisa data Hidrologi

1) Penghitungan data curah hujan rata-rata

2) Penghitungan intensitas hujan

3) Penghitungan debit kawasan 
b. Analisa Hidrolika

1) Penghitungan kapasitas saluran

2) Penghitungan debit penampungan

\section{HASIL DAN PEMBAHASAN}

\section{Analisis Curah Hujan}

Data curah hujan yang dipergunakan adalah data curah hujan maksimum tahunan, didapatkan dari Dinas Pertanian Kabupaten Ogan Komering Ulu. Dalam kurun waktu 10 tahun (2009-2018) yang terdapat pada tabel berikut :

Tabel 1 Data Curah Hujan Harian Maksimum (mm)

\begin{tabular}{|c|c|c|}
\hline No & Tahun & Curah Hujan Harian Maksimum (mm) \\
\hline 1 & 2009 & 20,3 \\
\hline 2 & 2010 & 39,2 \\
\hline 3 & 2011 & 16,3 \\
\hline 4 & 2012 & 45,8 \\
\hline 5 & 2013 & 31,4 \\
\hline 6 & 2014 & 21,2 \\
\hline 7 & 2015 & 25,2 \\
\hline 8 & 2016 & 21 \\
\hline 9 & 2017 & 27,1 \\
\hline 10 & 2018 & 26,4 \\
\hline
\end{tabular}

Sumber : Dinas Pertanian OKU, 2019

Adapun metode distribusi yang akan di gunakan adalah metode distribusi Gumble, metode Log Pearson type III dan Log Normal dengan uraian sebagai berikut :

Metode Distribusi Normal

Tabel. 2 Analisis Frekuensi dengan Metode Distribusi Normal

\begin{tabular}{|c|r|r|r|r|}
\hline Tahun & $\boldsymbol{R}_{\boldsymbol{i}}$ & \multicolumn{1}{c|}{$\left(\boldsymbol{R}_{\overline{\boldsymbol{i}}}-\boldsymbol{R}_{\boldsymbol{i}}\right)$} & $\left(\boldsymbol{R}_{\overline{\boldsymbol{i}}}-\boldsymbol{R}_{\boldsymbol{i}}\right)^{\mathbf{2}}$ & $\left(\boldsymbol{R}_{\overline{\boldsymbol{i}}}-\boldsymbol{R}_{\boldsymbol{i}}\right)^{\mathbf{3}}$ \\
\hline 2009 & 20,300 & $-7,090$ & 50,268 & $-356,401$ \\
\hline 2010 & 39,200 & 11,810 & 139,476 & 1647,213 \\
\hline 2011 & 16,300 & $-11,090$ & 122,988 & $-1363,938$ \\
\hline 2012 & 45,800 & 18,410 & 338,928 & 6239,666 \\
\hline 2013 & 31,400 & 4,010 & 16,080 & 64,481 \\
\hline 2014 & 21,200 & $-6,190$ & 38,316 & $-237,177$ \\
\hline 2015 & 25,200 & $-2,190$ & 4,796 & $-10,503$ \\
\hline 2016 & 21,000 & $-6,390$ & 40,832 & $-260,917$ \\
\hline 2017 & 27,100 & $-0,290$ & 0,084 & $-0,024$ \\
\hline 2018 & 26,400 & $-0,990$ & 0,980 & $-0,970$ \\
\hline $\bar{\Sigma}$ & 273,900 & & 752,749 & 5721,429 \\
\hline
\end{tabular}

Rata-rata $\bar{R}_{i}=\frac{\sum \mathrm{R}_{\mathrm{i}}}{\mathrm{n}}=\frac{273,9}{10}=27.39 \mathrm{~mm}$ 
Standar deviasi $S=\sqrt{\frac{1}{n-1} \sum(R i-\bar{R} i)^{2}}=\sqrt{\frac{1}{10-1} \times \mathbf{7 5 2 , 7 4 9}}=9.145$

Tabel 3 Variabel Reduksi Gauss (k) Distribusi Normal

\begin{tabular}{|c|c|c|c|c|}
\hline Periode & $\mathbf{2}$ & $\mathbf{5}$ & $\mathbf{1 0}$ & $\mathbf{2 0}$ \\
\hline Ulang (T) & 0 & 0.84 & 1.28 & 1.64 \\
\hline
\end{tabular}

Sumber: Soewarno, 1995

Penghitungan curah hujan dengan metode Distribusi Normal

$R_{T}=\bar{R}_{1}+K . S$

$R_{2}=27.39+(0)(9.145)=27.39 \mathrm{~mm}$

$R_{5}=27.39+(0.84)(9.145)=35.072 \mathrm{~mm}$

$R_{10}=27.39+(1.28)(9.145)=39.096 \mathrm{~mm}$

$R_{20}=27.39+(1.64)(9.145)=42.388 \mathrm{~mm}$

Metode Distribusi Log Pearson Type III

Tabel 4. Analisis Frekuensi dengan Metode Distribusi Log Pearson Type III

\begin{tabular}{|c|c|c|c|c|c|}
\hline Tahun & $\mathrm{Ri}$ & Log Ri & $\begin{array}{c}(\log R i- \\
\operatorname{LogR} i)\end{array}$ & $\left(\begin{array}{l}\log R i- \\
\operatorname{LogR} i)^{2}\end{array}\right.$ & $\begin{array}{l}(\log R i- \\
\log R i)^{3}\end{array}$ \\
\hline 2008 & 20,3 & 0,307 & $-1,130$ & 1,277 & $-1,443$ \\
\hline 2009 & 39,2 & 0,593 & $-0,844$ & 0,713 & $-0,602$ \\
\hline 2010 & 16,3 & 0,212 & $-1,225$ & $\begin{array}{r}-1,502 \\
\end{array}$ & $-1,840$ \\
\hline 2011 & 45,8 & 0,661 & $-0,777$ & 0,603 & $-0,469$ \\
\hline 2012 & 31,4 & 0,497 & $-0,941$ & 0,885 & $-0,832$ \\
\hline 2013 & 21,2 & 0,326 & $-1,111$ & 1,235 & $-1,372$ \\
\hline 2014 & 25,2 & 0,401 & $-1,036$ & 1,074 & $-1,113$ \\
\hline 2015 & 21 & 0,322 & $-1,115$ & 1,244 & $-1,388$ \\
\hline 2016 & 27,1 & 0,433 & $-1,005$ & 1,009 & $-1,014$ \\
\hline 2017 & 26,4 & 0,422 & $-1,016$ & 1,032 & $-1,049$ \\
\hline $\bar{\Sigma}$ & 273,9 & 4,175 & $-10,201$ & 10,574 & $-11,121$ \\
\hline Log Ŕi & 1,438 & & & & \\
\hline
\end{tabular}

Untuk menghitung Log Rí

$\log \overline{\mathrm{R}} \mathrm{i}=\frac{\sum \mathrm{R}_{\mathrm{i}}}{\mathrm{n}}=\frac{273_{\imath} 9}{10}=1,438$ 
Standar deviasi (Simpangan Baku)

$S \log \overline{\mathrm{R}} \mathrm{i}=\sqrt{\frac{\sum\left(\log R i-\log _{\mathrm{L} i}\right)}{\mathrm{n}-1}} \quad=\sqrt{\frac{10,574}{10-1}}=1.083$

Tabel 5 Nilai K untuk Cs, Distribusi Log Pearson Type III

\begin{tabular}{|c|c|c|c|c|c|}
\hline $\begin{array}{c}\text { Periode Ulang } \\
\text { (T) }\end{array}$ & $\mathbf{2}$ & $\mathbf{5}$ & $\mathbf{1 0}$ & $\mathbf{2 0}$ & $\mathbf{5 0}$ \\
\hline $\mathrm{K}$ & 0.116 & 0.857 & 1.183 & 1.386 & 1.663 \\
\hline
\end{tabular}

Sumber : Soewarno, 1995

Untuk menghitung Curah Hujan dengan metode Distribusi Log Pearson Type III

$\log \mathrm{R}_{\mathrm{T}}=\log \overline{\mathrm{R}} \mathrm{i}+\mathrm{KS}$

$\log \mathrm{R} 2=1,438+(0.116)(1.083)=1,564$

$\mathrm{R} 2=36,643 \mathrm{~mm}$

$\log \mathrm{R} 5=1,438+(0.857)(1.083)=2,366$

$\mathrm{R} 5=232,274 \mathrm{~mm}$

$\log \mathrm{R} 10=1,438+(1.183)(1.083)=2,719$

$\mathrm{R} 10=523,600 \mathrm{~mm}$

$\log \mathrm{R} 20=1,438+(1.386)(1.083)=2,939$

$\mathrm{R} 20=868,960 \mathrm{~mm}$

Rekapitulasi analisa curah hujan untuk data curah hujan maksimum dengan 3 metode distribusi, yaitu distribusi normal, distribusi Log Pearson Type III dan Distribusi Gumbel dapat dilihat pada tabel berikut :

Tabel 6. Rekapitulasi Analisa Frekuensi Curah Hujan Maksimum

\begin{tabular}{|c|c|c|c|}
\hline \multirow{2}{*}{$\begin{array}{c}\text { Periode } \\
\text { Ulang } \\
(\text { T) }\end{array}$} & \multicolumn{3}{|c|}{$\begin{array}{c}\text { Analisa Frekuensi Curah Hujan } \\
\text { Maksimum }\end{array}$} \\
\cline { 2 - 4 } & $\begin{array}{c}\text { Log } \\
\text { Normal }\end{array}$ & $\begin{array}{c}\text { Log Pearson } \\
\text { Type III }\end{array}$ & Gumbel \\
\hline 2 & $27.39 \mathrm{~mm}$ & $36,643 \mathrm{~mm}$ & $26,184 \mathrm{~mm}$ \\
\hline 5 & $35.072 \mathrm{~mm}$ & $232,274 \mathrm{~mm}$ & $37,101 \mathrm{~mm}$ \\
\hline 10 & $39.096 \mathrm{~mm}$ & $523,600 \mathrm{~mm}$ & $44,329 \mathrm{~mm}$ \\
\hline 20 & $42.388 \mathrm{~mm}$ & $868,960 \mathrm{~mm}$ & $51,261 \mathrm{~mm}$ \\
\hline
\end{tabular}

\section{Analisa Debit}

\section{Analisa Debit Rumah Tangga}

Jumlah debit air rumah tangga berkaitan dengan jumlah penduduk yang ada, jumlah penduduk yang ada di kelurahan Baturaja Permai sampai dengan akhir tahun 2018 adalah 5833 jiwa. Luas catchment area hanya 2,8\% dari luas kelurahan Baturaja Permai yaitu sebesar $1200 \mathrm{Ha}$, maka jumlah penduduk disesuiakan dengan persentase wilayah pengaliran yang ditinjau. Diperoleh jumlah penduduk adalah sebagai berikut : Jumlah penduduk $=2,8 \%$ × $5833=163,324$ jiwa 
Untuk perhitungan debit air limbah rumah tangga digunakan standar pemakaian air bersih direncanakan 165 liter/jiwa/liter, menggunakan persamaan 18 sebagai berikut:

$$
\begin{aligned}
& \mathrm{Q}_{\text {limbah }}=70 \% \times \mathrm{p} \times \mathrm{q} \\
& =0,7 \times 163,324 \times 165 \text { liter/jiwa/liter } \\
& =18863,922 \text { liter/jiwa/hari } \\
& =\frac{18863_{,} 922}{1000}=18,864 \mathrm{~m}^{3} / \text { har } i \\
& =\frac{18,864 \mathrm{~m}^{\mathrm{g}}}{24 \text { jam. } 60 \text { menit } .60 \text { detik }^{2}} \\
& =\frac{18,864 \mathrm{~m}^{\mathrm{g}}}{86400 \text { detik }} \\
& =0,000218 \mathrm{~m}^{3} / \operatorname{detik}
\end{aligned}
$$

\section{Analisa Debit Hujan}

Metode yang digunakan dalam memperkirakan debit puncak air hujan adalah metode rasional menggunakan persamaan 17 metode rasional ini digunakan karena daerah pengaliran yang ditinjau relative kecil, yaitu kurang dari $300 \mathrm{Ha}$. Debit yang dihitung adalah debit yang ditampung oleh saluran primer, seluran sekunder I dan saluran sekunder II dengan memperhitungkan jumlah/limpasan air dari seluruh daerah pengaliran.

Tabel 7. Rekapitulasi Analisa Debit Hujan

\begin{tabular}{|c|c|c|c|c|c|c|}
\hline No & Saluran & $\begin{array}{r}\text { Luasan } \\
(\mathbf{A})\left(\mathbf{m}^{2}\right)\end{array}$ & $\begin{array}{c}\text { Koef. } \\
\text { Pengaliran } \\
(\mathbf{C})\end{array}$ & $\begin{array}{c}\text { Intensitas } \\
\text { Hujan (I) } \\
(\mathbf{m} / \mathbf{d e t i k})\end{array}$ & $\begin{array}{c}\mathbf{Q}_{\text {Qujan }} \\
\left(\mathbf{m}^{\mathbf{3}} / \mathbf{d e t i k}\right)\end{array}$ & $\begin{array}{c}\mathbf{Q}_{\text {maks }} \\
\left(\mathbf{m}^{\mathbf{3}} / \mathbf{d e t i k}\right)\end{array}$ \\
\hline 1 & Primer & 40.000 & 0,70 & 0,000093 & 0,724 & 0,724 \\
\hline 2 & Sekunder I & 20.000 & 0,70 & 0,000093 & 0,362 & 0,362 \\
\hline 3 & Sekunder II & 30.000 & 0,70 & 0,000093 & 0,543 & 0,543 \\
\hline
\end{tabular}

Analisa Kapasitas Saluran

Dari hasil pengamatan langsung dilapangan, diketahui bahwa tipe salurannya yaitu saluran dengan penampang trapesium dan segi empat.

Tabel 8. Hasil Rekapitulasi Analisis Kapasitas Saluran

\begin{tabular}{|c|c|c|c|}
\hline $\begin{array}{c}\text { Saluran } \\
\text { Eksisting }\end{array}$ & $\begin{array}{c}\mathbf{Q}_{\text {saluran }} \\
\left(\mathbf{m}^{\mathbf{3}} / \mathbf{d e t i k}\right)\end{array}$ & $\begin{array}{c}\text { Qmax.saluran } \\
\left(\mathbf{m}^{\mathbf{3}} / \mathbf{d e t i k}\right)\end{array}$ & Keterangan \\
\hline Primer & 0,561 & 0,724 & Tidak Layak \\
\hline Sekunder I & 1,0233 & 0,3622 & Layak \\
\hline Sekunder II & 0,6987 & 0,5432 & Layak \\
\hline
\end{tabular}




\section{KESIMPULAN}

Berdasarkan hasil analisis data-data hidrologi terhadap drainase di Perumahan Baturaja Permai, maka didapat beberapa kesimpulan antara lain sebagai berikut ini:

a. Daya tampung saluran Primer yang ada saat ini tidak memadai untuk menampung debit maksimum maka direncanakan ulang saluran primer dengan analisa kebutuhan 5 tahun kedepan:
1) Saluran Primer Awal $=Q_{\text {saluran }}<Q_{\text {maksimum }}$ $0,561 \mathrm{~m}^{3} /$ detik $<0,724 \mathrm{~m}^{3} /$ detik
2) Saluran Primer Rencana $=Q_{\text {saluran }}<Q_{\text {maksimum }}$ $0,826 \mathrm{~m}^{3} /$ detik $<0,724 \mathrm{~m}^{3} /$ detik

b. Sedangkan untuk daya tampung saluran Sekunder yang ada masih memadai untuk menampung debit maksimum:
1) Saluran Sekunder I
$=\mathrm{Q}_{\text {saluran }}>\mathrm{Q}_{\text {maksimum }}$ $1,0233 \mathrm{~m}^{3} /$ detik $>0,3622 \mathrm{~m}^{3} /$ detik
2) Saluran Sekunder II
$=\mathrm{Q}_{\text {saluran }}>\mathrm{Q}_{\text {maksimum }}$ $0,6987 \mathrm{~m}^{3} /$ detik $>0,5432 \mathrm{~m}^{3} /$ detik

c. Penyebab terjadinya genangan/banjir adanya limpasan dari saluran utama dan limpasan air rawa. Serta pendangkalan, kerusakan dan penyumbatan sampah disaluran ini.

\section{DAFTAR PUSTAKA}

Andy Yarzis Qurniawan. 2009. Perencanaan Sistem Drainase Perumahan Josroyo Permai RW II Kecamatan Jaten Kabupaten Karanganyar. Jurnal. Universitas Sebelas Maret Surakarta.

Limpat Ovi Haryoko. 2013. Evaluasi dan Rencana Pengembangan Sistem Drainase di Kecamatan Tanjungkarang Pusat Bandar Lampung. Jurnal. Universitas Malahayati Bandar Lampung.

H.A. Halim Hasmar, 2011. Drainase Terapan. UII Press Yogyakarta: Yogyakarta

Hasmar,H (2011:8) dalam Amiwarti (2017), https://jurnal.univpgri-palembang.ac.id/ index.php/deformasi/article/view/1199/1036

Robert J. Kodoatie. 2005. Pengantar Manajemen Infrastruktur. Pustaka Pelajar: Yogyakarta.

Sosrodarsono, S. 1997. Drainase Perkotaan. Penerbit: Gunadarma.

Suripin, 2004. Sistem Drainase Perkotaan yang Berkelanjutan. Andi Offset: Yogyakarta.

Wahyu Indra Kusuma. 2016. Perencanaan Sistem Drainase Kawasan Perumahan Green Mansion Residence Sidoarjo. Jurnal. Institut Teknologi Sepuluh Nopember. 